\title{
Evaluating detectability of freshwater fish assemblages in tropical streams: Is hand-seining sufficient?
}

\author{
Amy E. Deacon • Rajindra Mahabir • Devan Inderlall • \\ Indar W. Ramnarine • Anne E. Magurran
}

Received: 18 February 2016 / Accepted: 23 April 2017 /Published online: 1 June 2017

(C) The Author(s) 2017. This article is an open access publication

\begin{abstract}
Unprecedented threats to natural ecosystems mean that accurate quantification of biodiversity is a priority, particularly in the tropics which are underrepresented in monitoring schemes. Data from a freshwater fish assemblage in Trinidad were used to evaluate the effectiveness of hand-seining as a survey method in tropical streams. We uncovered large differences in species detectability when hand-seining was used alone, in comparison with when hand-seining and electrofishing were used together. The addition of electrofishing increased the number of individuals caught threefold, and increased the biomass fivefold. Some species were never detected using hand-seining, resulting in significant underestimates of species richness; rarefaction curves suggest that even when hand-seining effort increases, species richness is still underestimated. Diversity indices (Shannon and Simpson index) reveal that diversity was also significantly lower for handseined samples. Furthermore, the results of multivariate analyses investigating assemblage structure also differed significantly depending on whether they were based on hand-seined data alone, or a combination of hand-seining and electrofishing. Despite the extra equipment and maintenance required, these findings
\end{abstract}

\footnotetext{
A. E. Deacon $(\bowtie) \cdot$ A. E. Magurran

Centre for Biological Diversity, School of Biology, University of St Andrews, St Andrews, UK

e-mail: amy.deacon@sta.uwi.edu
}

A. E. Deacon - R. Mahabir - D. Inderlall - I. W. Ramnarine Department of Life Sciences, The University of the West Indies, St Augustine Campus, St Augustine, Trinidad and Tobago underline the value of including electrofishing when sampling tropical freshwater streams.

Keywords Trinidad Electrofishing - Alpha diversity . Detectability $\cdot$ Species richness $\cdot$ Sampling methods . Gear bias

\section{Introduction}

Detectability is an important but often overlooked factor in biodiversity assessment and monitoring (Buckland et al. 2011). Depending on the survey methods and the habitat, certain species are more easily sampled than others (Boulinier et al. 1998). This bias is important, as measures of diversity assume that samples are representative of the community sampled (Magurran 2004). Variation in detectability between species can therefore have important implications for interpreting measures of diversity (see Yoccoz et al. 2001).

Issues of detectability are particularly pertinent to freshwater communities. Despite covering just $1 \%$ of the Earth's surface, freshwater habitats are estimated to support $6 \%$ of all described species - a fact that is not yet reflected in the corresponding amount of research effort (Abell 2002; Dudgeon et al. 2006). Neotropical freshwaters are also one of the most threatened habitats in the world (Balmford et al. 2002; WWF 2014), yet knowledge of their biodiversity is limited. Understanding and monitoring neotropical freshwaters is necessary for their conservation, and effective sampling is needed to address this research gap. Detectability needs to be 
considered in these investigations (Gotelli and Colwell 2011), especially as different fish species can have markedly different habits, ranging from those that tend to reside in the water column, including those that form shoals, to benthic species that hide in crevices or under stones on the river bed.

In freshwater streams, the most effective way to get around issues of detectability is to use a piscicide such as rotenone, which kills all fish in the treated stretch without biases related to ecology or size (Głowacki and Penczak 2005), yet in doing so destroys the biodiversity the investigator has set out to quantify.

Both hand-seining and electrofishing are commonlyused, non-lethal methods for surveying fish assemblages in shallow streams and rivers (e.g., Maciolek and Timbol 1980; Willis et al. 2005; Gerstner et al. 2006). There are advantages and disadvantages to each, both in terms of detectability and practicalities. Handseining uses simple, easy-to-transport equipment and is considered efficient in terms of cost and labour. However, it is less well-suited to streams characterised by obstructions such as rocks and vegetation which make effective hand-seining harder, both by preventing the smooth passage of the net, and by providing places for benthic fish to seek refuge. Conversely, electrofishing can be effective at drawing fish out of cover (Dauble and Gray 1980; Cote and Perrow 2006) and is thought to be less selective overall than many other methods (see Fièvet et al. 1999; Hendricks et al. 1980). Nonetheless, it is not well suited to deep, turbid pools or very low conductivity conditions. There are also safety considerations for the operator, especially when using a backpack, and if using a bank-side generator then there is heavy equipment to transport (Onorato et al. 1998). Furthermore, there are ethical considerations for the fish; there can be mortality if individuals inadvertently sustain prolonged exposure to electric current, albeit at low levels (Snyder 2003; Cote and Perrow 2006).

Both approaches are potentially subject to gearrelated size-biases. Electrofishing tends, on average, to catch larger individuals than hand-seining (Dauble and Gray 1980; Wiley and Tsai 1983). Mechanisms may include the differential vulnerability of different-sized individuals to immobilisation by electric current (Dolan and Miranda 2003) as well as behavioural differences (Zalewski 1983; Bohlin et al. 1989).

Many researchers advocate the use of a combination of different non-lethal sampling methods with the aim of achieving a more representative sample of the community than any one method alone (Colwell and Coddington 1995; Onorato et al. 1998; Ebner and Morgan 2013), for example combining electrofishing and seining (Fago 1998). However, an additional consideration is that, especially in the tropics, expensive electrofishing equipment is not always available. This gear can also be more difficult to maintain in hot, humid conditions. Tropical forest streams are often hard to access, and necessitate transporting heavy equipment through difficult terrain (Ebner et al. 2014). This leads us to question whether electrofishing is worth the considerable additional effort in such environments.

Here we examine detectability in a tropical freshwater fish assemblage using hand-seining alone, and handseining in combination with electrofishing. We do this in the context of the assessment of diversity and compare the abundance, diversity and assemblage structure of fishes caught using the two approaches. We focus on the numerous parallel streams of Trinidad's Northern Range that have been widely used as a model system for evolutionary and ecological studies (see Magurran 2005), and where the fish fauna is well documented (Phillip et al. 2013). Our aim is to use this wellreplicated system to assess whether surveys of tropical freshwater stream fishes that rely solely on hand-seining provide adequate assessments of biodiversity and are free from bias due to detectability issues.

\section{Methods}

Sampling methods

\section{Location and site features}

Sixteen sites along the southern slopes of Trinidad's Northern Range (Fig. 1) were surveyed repeatedly (13 times) over a 3-year period as part of a longitudinal biodiversity study. Each site consisted of a variety of habitats, including pools and riffles, and many of the sites included portions of undercut banks. Water conductivity was measured before each survey; almost all readings fell between 100 and $400 \mu \mathrm{S} / \mathrm{cm}$ (mean: $252 \mu \mathrm{S} / \mathrm{cm} \pm \mathrm{SD} 97)$. No sites were considered 'low' conductivity ( $>43 \mu \mathrm{S} / \mathrm{cm}$ ), which can reduce electrofishing efficiency in some neotropical streams (Allard et al. 2014).

Surveys always took place between 08:00 and 11:00 and were spread throughout the year to include both dry 


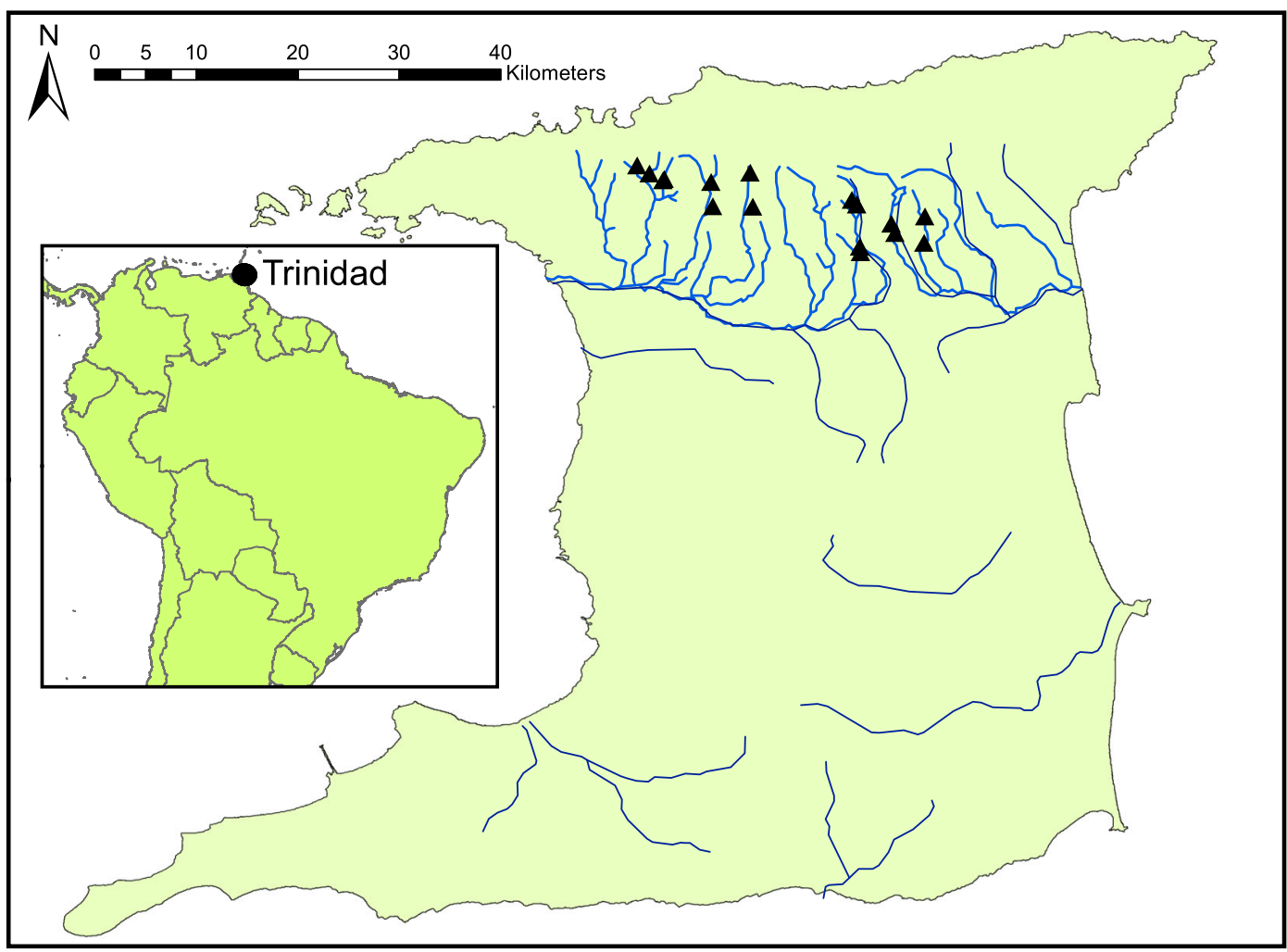

Fig. 1 Trinidad's position in relation to South America, and the distribution of the 16 sampling sites (black triangles) along the streams of the southern slopes of the island's Northern Range mountains. Other major rivers are also shown

and rainy season conditions. Water depth was measured at $1 \mathrm{~m}$ intervals along three transverse transects at each site; maximum depth at any site was $1.88 \mathrm{~m}$ and the mean depth over all transects at all sites was $24( \pm$ SD 22$) \mathrm{cm}$. Turbidity was measured on a visually assessed scale of $1-5$, where one is clear and five is opaque (see Deacon et al. 2015 for details). The median turbidity was 1.28 (with a lower quartile of 1 and an upper quartile of 2); we report the median value here in light of the categorical nature of the scale. Substrata varied within and between sites; on average the stream bed was covered by $36.9 \%( \pm$ SD 9.5) fine substrates (silt, sand, gravel) and $30.5 \%( \pm$ SD 10.4$)$ coarse substrates (cobble, boulders). Flow rate was low to moderate across sites with a mean of $0.31( \pm$ SD 0.15$) \mathrm{m} / \mathrm{s}$, and only occasionally exceeded $1 \mathrm{~m} / \mathrm{s}$.

Each site comprised a $50 \mathrm{~m}$ stretch of stream, blocked at both ends by seine nets. During a survey, each stretch was systematically fished from one end to the other, first using a two-person hand seine (64 $\mathrm{mm}$ mesh), and then again with electrofishing equipment.

\section{Hand-seining}

Different sized hand seines were used depending on the dimensions of the site; all were $1.5 \mathrm{~m}$ high and between 2 and $3 \mathrm{~m}$ long, with wooden poles, floats along the top and weights along the bottom. The seine was pulled wherever physically possible along the stretch (all parts of the stream with the exception of the shallowest riffles and smallest pools); three passes were made and these constituted one sample. Each pass consisted of the operators starting at one end of the site and systematically fishing from one end to the other.

\section{Electrofishing}

The electrofishing equipment consisted of a portable generator (Yamaha EF1000is) on the bank, linked to two hand-operated poles with a safety switch. Both operators wore rubber waders, and while one operated the poles, the other stood nearby with a landing net and bucket to scoop up the stunned fishes. A double pass was made along the entire length of the $50 \mathrm{~m}$ stretch. 
The operators were experienced in applying these techniques in these environments and the same two operators were involved in all surveys.

\section{Fish handling}

Fish were kept in shaded buckets, separated according to the method with which they were caught. Care was taken to separate predators from their prey and to keep densities low. Fishes were identified to species level and weighed individually to the nearest gram using a small plastic container on a portable electronic balance. This represents wet weight and is referred to as 'biomass' from here on. The fish caught by hand-seining were not released until the electrofishing was complete. All fish were released unharmed at the end of each survey.

\section{Analysis}

\section{Species differences}

Abundance data from all 208 surveys (13 surveys at each of the 16 sites) were combined and the percentage of total catch attributed to hand-seining alone, and for both methods together, was calculated for each species. Any species that were represented by fewer than five individuals over all 16 sites were omitted from this analysis, as meaningful percentages could not be calculated from such a small number (i.e. a single individual has too much influence on the overall percentage). These species were, however, included in all subsequent analyses (i.e. computations of $\alpha$ diversity and multivariate analyses).

\section{Alpha $(\alpha)$ diversity}

To test how sampling method influences our assessment of $\alpha$ diversity, we calculated the abundance of each species at each of the 16 sites (number of individuals per species, per site, summed over the 13 repeat surveys) for both fishing methods (hand-seining alone and hand-seining and electrofishing data combined). All species caught were included in these analyses. We also calculated total number of individuals (N) (summed over 13 surveys), and mean fish biomass (mean of 13 surveys) at each site for both methods (hand-seining, and hand-seining and electrofishing combined). These metrics are widely used in the monitoring of freshwater assemblages.
We next calculated three popular measures of $\alpha$ diversity (richness, Shannon and Simpson diversity) for each of the 208 surveys; first using the hand-seining data alone, and again using the data from the hand-seining and electrofishing combined. Species richness (S) is the most intuitive measure of diversity, but most affected by sampling effort. The Shannon index $\left(\mathrm{H}^{\prime}\right)$ takes the relative abundance of different species into account while the Simpson index (1/D) places greater weight on species dominance (Magurran 2004). To evaluate differences between sampling methods, species richness and Shannon diversity (log transformed, to meet ANOVA assumptions) were analysed using a two-way ANOVA with method and season as fixed factors. Because Simpson index values did not meet the assumptions of a parametric test, even after transformation, a non-parametric analogue of ANOVA [Scheirer-Hare-Ray test (Dytham 2011)] was employed. Surveys conducted between June and December were considered rainy season surveys, while those conducted between January and May were considered dry season surveys (http://www.metoffice.gov.tt/Climate).

Rarefaction provides researchers with a means of making a fair comparison between sites or studies where there has been a difference in sampling effort (Gotelli and Colwell 2001). However, estimates of richness obtained using rarefaction may be biased if different sampling methods favour different taxa. To ascertain whether this problem arises when the different fishing methods employed in our study are used, we estimated species richness for the entire assemblage (that is, all 16 sites) by computing sample-based rarefaction for handseined data alone and data from hand-seining and electrofishing combined. These calculations were carried out using Estimate S v. 9.1.0 (Colwell 2013) to implement eq. 17 in Colwell et al. (2012). For each sampling method a rarefaction curve, with $95 \%$ confidence intervals, was constructed.

\section{Multivariate methods}

Multivariate methods are widely used in ecology to summarise and interpret community data. We applied three multivariate techniques: PERMANOVA (Anderson 2001), cluster analysis (Galili 2015), and NMDS (Oksanen et al. 2008), to shed additional light on the extent to which the two fishing methods (handseining and combined hand-seining and electrofishing) shape our perception of biodiversity in these neotropical streams. 
PERMANOVA, an informative and appropriate alternative to ANOVA when testing for differences in ecological data (Anderson 2001), is based on distance measures and uses permutation to generate pseudo-F ratios. We employed PERMANOVA to evaluate differences between the two fishing methods (hand-seined data and combined data). This analysis was computed using overall species abundances at each site (with a $\log 10 \mathrm{x}+1$ transformation) in $\mathrm{R}$ (RCoreTeam 2016), using the adonis function in the vegan package (Oksanen et al. 2008).

Cluster analysis provides a visual summary of the relationship between entities for which there are multivariate data and is often used to represent the relationship between localities. We used this approach to examine the pattern of classification of sites obtained using the different fishing methods. A cluster analysis of sites, one per method, was constructed in R (RCoreTeam 2016) using Euclidian distance and the 'complete' clustering algorithm. Using the dendextend package in $\mathrm{R}$ (Galili 2015), a tanglegram was then constructed to illustrate the concordance in clustering outcomes achieved using the different methods.

Nonmetric Multidimensional Scaling (NMDS) is an ordination method based on distance data and an effective tool for describing ecological patterns. We thus employed NMDS [metaMDS in the vegan package (Oksanen et al. 2008)] to represent the ecological placement of fish species, relative to one another, as deduced when hand-seining is used alone, or when hand-seining data and electrofishing data are combined. All univariate statistical tests were performed using IBM SPSS v.22. Multivariate statistics were performed using R v.3.3.2 (RCoreTeam 2016).

\section{Results}

Species differences

As is typical of ecological surveys, some species were common, while others were rare (Fig. 2). However, the coverage of a given species, that is its relative abundance in the overall data set, depended on the sampling method. For some species hand-seining accounted for the majority of individuals caught, while other species were completely missed using this method. Indeed, the percentage of total catch using hand-seining varied greatly according to species, spanning a wide range of values from $87 \%$ to zero (Fig. 2).
Three species [the swamp eel Synbranchus marmoratus (Bloch, 1795), the river goby Awaous banana (Valenciennes, 1837) and the knife fish Gymnotus carapo (L., 1758)] were never caught in the hand-seined samples even though electrofishing revealed their presence at four sites (on a total of five occasions). A further five species were caught by both methods but detected more often by electrofishing ( $<25 \%$ of individuals caught were caught by hand-seining): the silver catfish Rhamdia quelen (Quoy \& Gaimard, 1824), the armoured catfishes Ancistrus maracasae (Fowler, 1946) and Hypostomus robinii (Valenciennes, 1840), the featherfin tetra Hemigrammus unilineatus (Gill, 1858), and the wolf-fish Hoplias malabaricus (Bloch, 1794). Two species were represented well by the hand-seining ( $>80 \%$ of individuals caught were caught by hand-seining): Odontostilbe pulchra (Gill, 1858) and the swordtail sardine Corynopoma riisei (Gill, 1858). Around half of the total individuals caught of the blue acara Andinoacara pulcher (Gill, 1858), the twospotted sardine Astyanax bimaculatus (L., 1758), the mountain stream sardine Hemibrycon taeniurus (Gill, 1858 ) and the hunchback sardine Roeboides dientonito (Schultz, 1944) were caught using hand-seining.

The Trinidadian guppy, Poecilia reticulata, was not well-sampled by hand-seining or electrofishing; its small size $(<3 \mathrm{~cm})$ means that it passes through the mesh of the seine and the landing net. Guppies were present at all sites and sampled separately using dip nets during our surveys.

\section{Alpha $(\alpha)$ diversity}

Conclusions regarding total fish abundance were heavily dependent on fishing method. The number of individuals caught increased threefold, and the biomass recorded per site increased by five times, when data compiled using both methods combined were compared to the results from hand-seined sampling alone (Table 1).

Inferences about assemblage diversity were also shaped by methodological approach. Higher estimates of diversity were obtained when the combined data were used: species richness (ANOVA $F_{1,60}=9.94 p<0.001$; Table 1), Shannon index $\left(\mathrm{F}_{1,60}=14.33 ; p<0.001\right.$; Table 1) and Simpson index $\left(\mathrm{SS} / \mathrm{MS}_{\text {total }}=13.69\right.$; $p<0.001$; Table 1). There was no effect of season (all tests: $p>0.100$ ), nor significant interactions between method and season (all tests: $p>0.100$ ) for any of the 
Fig. 2 Species ranked according to the $\%$ caught by hand seining, illustrating considerable betweentaxa variation. Total $\mathrm{N}$ in parentheses on the $\mathrm{x}$-axis label

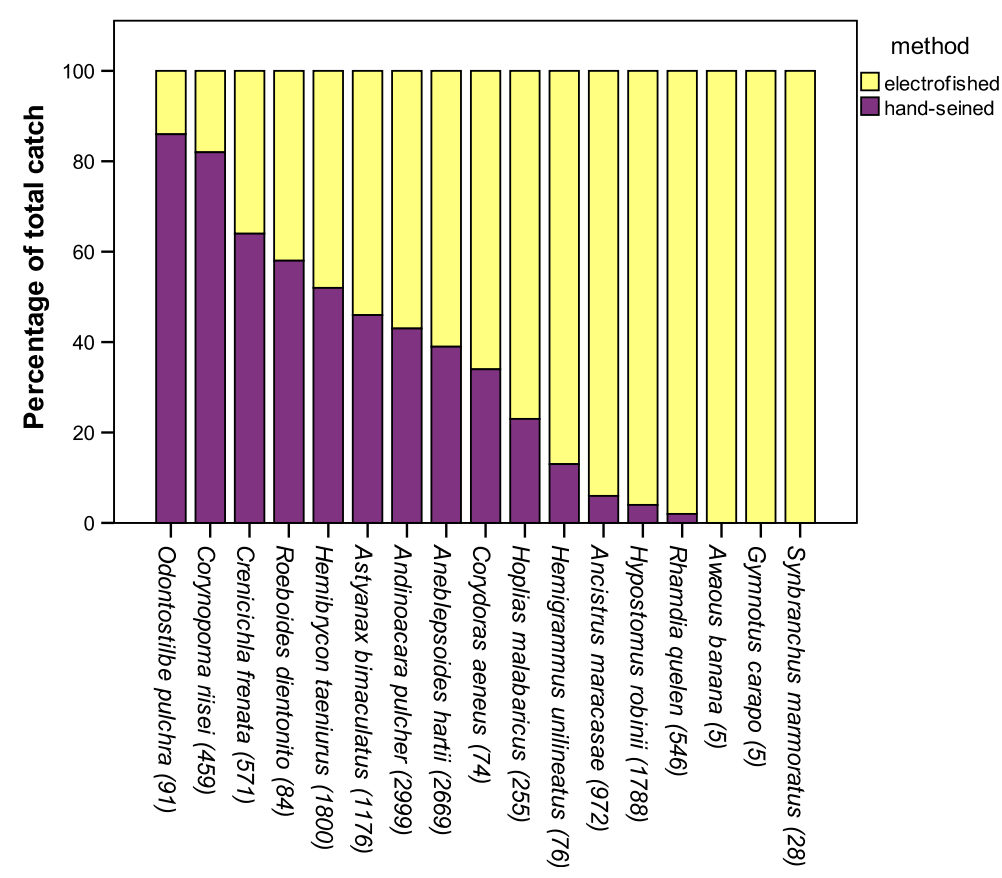

diversity metrics tested (species richness, Shannon index or Simpson index).

Our analyses further show that rarefaction cannot compensate for the methodological differences. Rarefaction curves illustrate the difference in estimates of species richness between hand-seining and combined fishing methods, and also show both curves reaching an asymptote at a similar point along the $\mathrm{x}$-axis (Fig. 3).

Multivariate measures of diversity

Multivariate approaches add additional support to the conclusion that fishing method profoundly influences perception of diversity, as well as helping to visualise these differences. The PERMANOVA revealed significant differences in assemblage structure between hand-seined samples and the combined hand-seined and electrofished samples $\left(\mathrm{F}_{1,30}=5.128 ; p<0.002\right.$; Fig. 4). Differences in the placement of sites in a cluster analysis is evident from the tanglegram (Fig. 5) and contrasts in the apparent ecological relationship of species apparent from the NMDS plots (Fig. 4). Taken together these results provide compelling evidence that conclusions about biodiversity and the structure of these fish assemblages are shaped by the sampling methods used to obtain the data (Fig. 5).

\section{Discussion}

A striking finding of this study is that sampling method has a far-reaching influence on the conclusions drawn about these tropical fish assemblages. Hand-seining was

Table 1 Hand-seining vs combined method. Includes all fish caught over 13 visits to each of the 16 sites

\begin{tabular}{llll}
\hline & Hand-seining only & Both methods combined & $p$-value \\
\hline Total N & 4958 & 14,015 & $\mathrm{n} / \mathrm{a}$ \\
Total biomass $(\mathrm{g})$ & 25,523 & 128,393 & $\mathrm{n} / \mathrm{a}$ \\
Mean biomass $(\mathrm{g})$ per visit & $122(\mathrm{SE} \pm 32)$ & $617(\mathrm{SE} \pm 98)$ & $\mathrm{n} / \mathrm{a}$ \\
Mean S per site & $7.31(\mathrm{SE} \pm 0.74)$ & $9.75( \pm \mathrm{SE} 0.93)$ & $<0.01^{* *}$ \\
Total S & 17 & 21 & $\mathrm{n} / \mathrm{a}$ \\
Mean Shannon $(\mathrm{H})$ per site & $0.50(\mathrm{SE} \pm 0.10)$ & $0.92(\mathrm{SE} \pm 0.13)$ & $<0.001^{* * *}$ \\
Mean Simpson (1/D) per site & $1.40(\mathrm{SE} \pm 0.14)$ & $2.02(\mathrm{SE} \pm 0.24)$ & $<0.001^{* * *}$ \\
\hline
\end{tabular}


Fig. 3 Rarefaction curves for hand-seined (dark grey) and combined (light grey) fish species richness data (S(est)), including 95\% confidence intervals. Calculated using Estimate $\mathrm{S}$ rarefaction (100 runs)

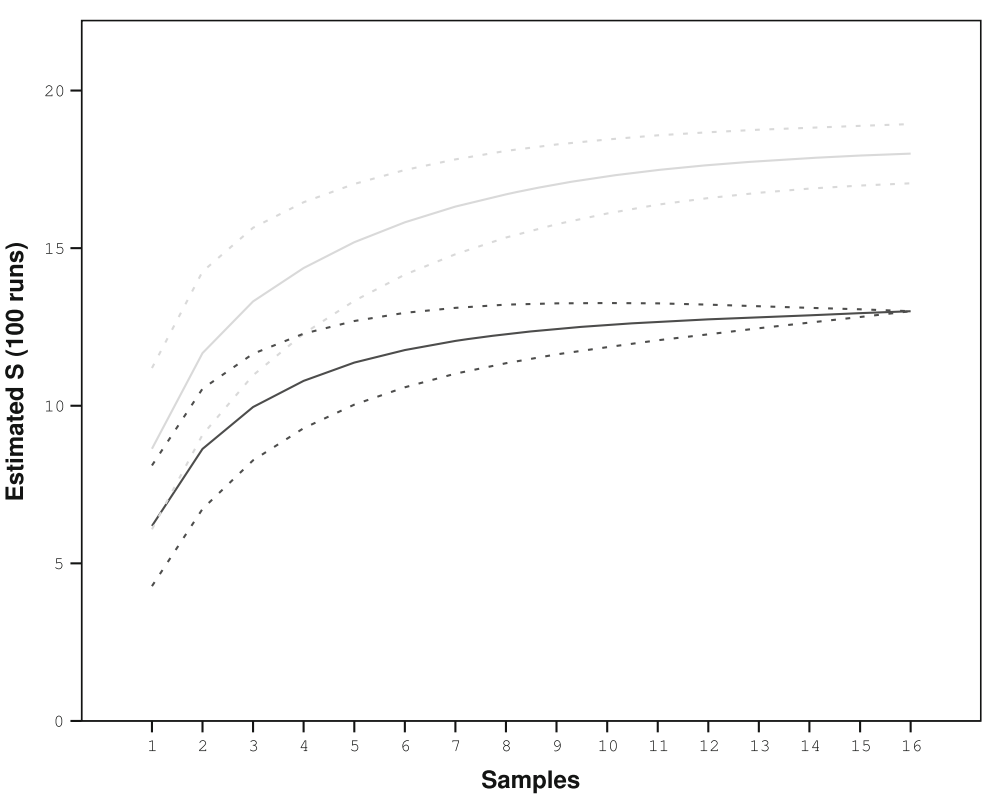

better at capturing some species than others, and tended to be more successful at sampling open water than benthic species. Had hand-seining been the only sampling technique used here, each of the assemblage properties measured (species richness, Simpson index, Shannon index and multivariate properties) would have been considerably different, and the subsequent conclusions would have been potentially misleading.

The species that were best-represented by the handseining tended to be the open water, shoaling characids. These species form large pelagic shoals, often in mixed species groups (Lowe-McConnell 1975). Although the order effects of this study prevented a direct comparison between the two methods, it appears that seining is best-suited to capturing shoals of fish, and this is primarily what it seine nets are designed to do (Lapointe et al. 2006; Mercado-Silva and Escandón-Sandoval 2008).

In contrast, the three species that were never caught by hand-seining (despite being detected by the electrofishing) were all solitary benthic fishes that tend to be found hiding in vegetation or on the river bottom where they can easily evade a seine net (Angermeier and Karr 1983). Similarly, although occasionally caught in the hand seine, the benthic catfishes were overwhelmingly better-represented in the electrofishing samples. This finding is supported by Mazzoni et al. (2000), who also found electrofishing to be effective for benthic species with cryptic habits, such as Rhamdia spp. and
Synbranchus spp. The result of this bias in the current study is that several benthic species would have been severely underrepresented - or even assumed absent had electrofishing not been used.

Not only does the hand-seined rarefaction curve plateau at a lower species richness, but the narrow 95\% confidence intervals it yields could lead to the false conclusion that all species in the habitat have been detected, and thus provide a dramatic underestimate of species richness. In fact, the difference in these curves can be attributed to the several species that are never, or very rarely, detected by hand-seining. This suggests that the difference in species richness is independent of effort, and that the estimate would never converge on the combined methods richness total, even given further hand-seining passes. This is an important observation as the premise of rarefaction is that a fair comparison is possible once sampling effort is controlled. What the analysis does highlight is that sampling effort implies not just the number of samples, but also the mode of sampling - a distinction easily overlooked. Of course, it is not possible to be sure that the combined methods detected every single species in the habitat, but it is clear that the hand-seining alone did not.

Our findings suggest that it is not simply the number of species that may be wrongly estimated in the absence of electrofishing. Had hand-seining alone been used to survey these sites, the proportional measures of diversity (Shannon and Simpson index) and multivariate analyses 

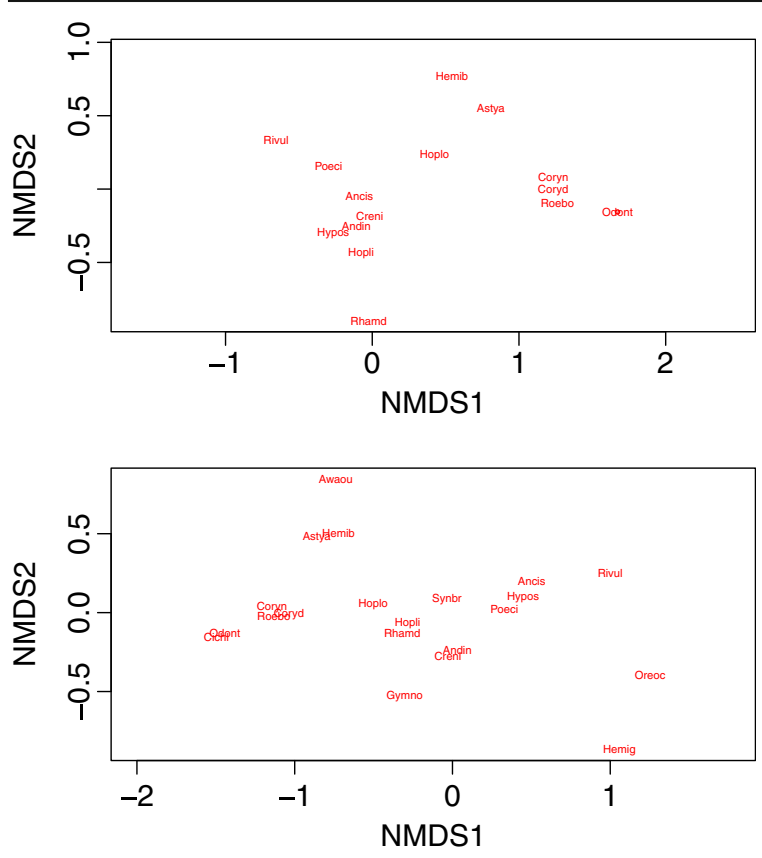

Fig. 4 NMDS plots for hand-seined (above) and combined (below) fish assemblage data. Stress values were 0.13 for the hand-seining data, and 0.08 for the combined data (values under $>0.2$ are generally considered a 'good' representation of the data). Key to species: Ancis = Ancistrus maracasae; Andin = Andinoacara pulcher; Astya = Astyanax bimaculatus; Awaou = Awaous banana; Cichl = Cichlasoma taenia $;$ Coryd = Corydoras aeneus; Coryn $=$ Corynopoma riseii $;$ Creni $=$ Crenicichla frenata; Gymno = Gymnotus carapo; Hemib = Hemibrycon taeniurus; Hemig = Hemigrammus bilineatus; Hopli = Hoplias malabaricus; Hoplo = Hoplosternum littorale; Hypos = Hypostomus robinii; Odont = Odontostilbe pulcra; Oreoc = Oreochromis mossambicus; Poeci $=$ Poecilia reticulata $;$ Roebo $=$ Roeboides dientonito; Rhamd = Rhamdia quelen; Rivul = Anablepsoides hartii; Synbr = Synbranchus marmoratus would have each pointed towards different interpretations of the structure and composition of these assemblages than those based on the results from the fuller dataset (with electrofishing). Such differences are not trivial, as they could lead to different decisions or recommendations regarding the management and conservation of freshwater habitats. Practitioners routinely use these types of indices and analyses to get a more nuanced picture of the structure of a community or assemblage. For example, multivariate analyses can reveal differences in $\beta$ diversity, concerning similarities between sites in the composition and structure of assemblages.

The comparison of $\alpha$ diversity indices is especially common in biodiversity monitoring programmes, therefore it is important to be aware that choice of sampling gear can have a significant effect on these. In a similar study of tropical Mexican streams, Mercado-Silva and Escandón-Sandoval (2008) also found that hand-seining significantly underestimated these types of metrics (in this case species richness, Shannon index and biomass). Such differences are not solely attributable to missing the rare, solitary species when hand-seining. For example, the benthic catfish, Hypostomus robinii, was one of the most abundant species across our sites, yet would have been considered a rare species if the hand-seine data alone had been examined. Our findings emphasise the importance of taking detectability, and how this might be affected by fishing methods, into account when interpreting measures of assemblage diversity.
Fig. 5 Tanglegram showing hierarchical clustering of sites according to similarities in fish assemblage, for hand-seined data (left) and combined data (right). Key to sites: $\mathrm{AD}=$ Acono Down; $\mathrm{AU}=$ Acono Up; $\mathrm{CD}=$ Caura Down; $\mathrm{CU}=$ Caura Up; $\mathrm{LAD}=$ Lower Aripo Down; $\mathrm{LAU}=$ Lower Aripo Up; LD = Lopinot Down; $\mathrm{LU}=$ Lopinot $\mathrm{Up} ; \mathrm{MD}=$ Maracas Down; MU = Maracas Up; QD = Quare Down; QU = Quare $\mathrm{Up}$; TD = Turure Down; $\mathrm{TU}=$ Turure Up; UAD = Upper Aripo Down; UAU = Upper Aripo Up

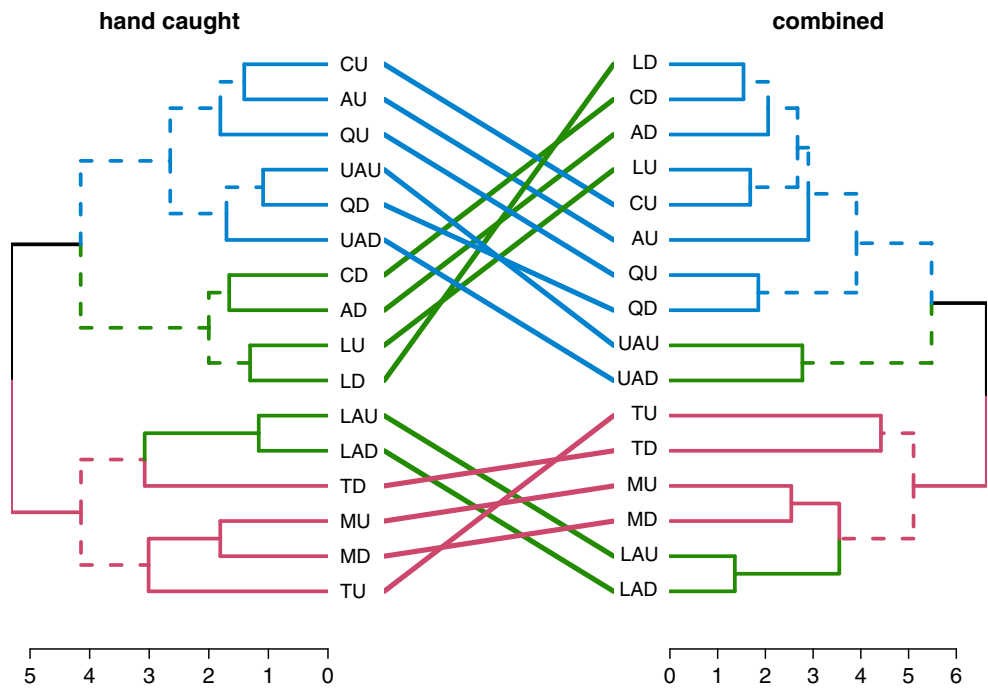


Although in our study, all three $\alpha$ diversity measures were simultaneously affected by gear type, this is not always the case, For example, Onorato et al. (1998) found that despite the proportions of different taxa differing between electrofished and hand-seined samples in streams in Alabama, species richness remained the same. These findings support the suggestion that electrofishing is better and more consistent in efficacy than seining (Wiley and Tsai 1983; Mercado-Silva and Escandón-Sandoval 2008) and that it is the most effective method for small to medium streams (Mazzoni et al. 2000). Results from electrofishing in French Guiana (Allard et al. 2014) and South Africa (Weyl et al. 2013) compare well with those obtained using destructive sampling with rotenone. Despite this, it is important to be aware of other stream properties that can affect the efficacy of either method. Conductivity is a particularly important one for electrofishing in neotropical streams, and although it was not an issue at our sites, low water conductivity $(>43 \mu \mathrm{S} / \mathrm{cm})$ can reduce the efficacy of electrofishing (Allard et el. 2014), and in these cases careful use of rotenone may need to be considered.

\section{Recommendations}

Given that electrofishing improved the detectability of fish assemblages at our sites, we recommend that it is employed alongside hand-seining in surveys of tropical streams, both in rainy and dry seasons. We are not the first to advocate the use of a combination of methods: Mercado-Silva and Escandón-Sandoval (2008) compared the two methods directly in their Mexican stream surveys, and found that at least one species was consistently underrepresented when electrofishing was conducted alone. Similarly, Pusey et al. (1998) found that combined electrofishing and hand-seining in streams of Queensland, Australia produced better estimates of total fish abundance, among other metrics, and Fago (1998) recommended a combination of different methods (including hand-seining and electrofishing) to get an accurate idea of species composition, based on Wisconsin stream surveys. The strength of our study is that it supports these findings using data from over 14,000 fish caught during a total of 208 surveys at 16 sites over 3 years, as well as demonstrating that multiple measures of biodiversity may be affected if electrofishing is not employed alongside handseining.

\section{Conclusions}

Despite the potential challenges of acquiring, maintaining, transporting and operating electrofishing equipment in the tropics, our study suggests that the additional effort will be rewarded with greater detection, resulting in more comprehensive and representative samples. This finding has important implications for the conservation and management of biodiversity. Rapid anthropogenic changes to freshwater habitats in many tropical regions, including to the very streams surveyed here (Deacon et al. 2015), mean that monitoring the effects of disturbance and land use change on biodiversity is increasingly important (Dudgeon et al. 2006). Neotropical assemblages in general are under growing threat (WWF 2014), while the ability of policy makers to respond appropriately is hampered by sparse data (Abell 2002). An understanding of the strengths and limitations of survey methods (depending on the habitat and the questions being addressed), is vital if we are to collect high quality data on threatened fish assemblages.

Acknowledgements This work was funded by a European Research Council grant (BIOTIME 250189). AEM also acknowledges the Royal Society. The authors are grateful to K. Deonarinesingh and A. Deonarinesingh for fieldwork assistance, F. Jones for constructing Fig. 1, and B. Ebner and two anonymous reviewers for comments on an earlier draft of this manuscript.

Compliance with Ethical Standards Research was conducted in line with the ethical guidelines of the European Research Council, the University of St Andrews' Animal Welfare and Ethics Committee, and The University of the West Indies' Policy and Procedures on Research Ethics.

Open Access This article is distributed under the terms of the Creative Commons Attribution 4.0 International License (http:// creativecommons.org/licenses/by/4.0/), which permits unrestricted use, distribution, and reproduction in any medium, provided you give appropriate credit to the original author(s) and the source, provide a link to the Creative Commons license, and indicate if changes were made.

\section{References}

Abell R (2002) Conservation biology for the biodiversity crisis: a freshwater follow-up. Conserv Biol 16:1435-1437

Allard L, Grenouillet G, Khazraie K, Tudesque L, Vigouroux R, Brosse S (2014) Electrofishing efficiency in low conductivity 
neotropical streams: towards a non-destructive fish sampling method. Fish Manag Ecol 21:234-243

Anderson MJ (2001) A new method for non-parametric multivariate analysis of variance. Austral Ecol 26:32-46

Angermeier PL, Karr JR (1983) Fish communities along environmental gradients in a system of tropical streams. Environ Biol Fish 9:117-135. doi:10.1007/BF00690857

Balmford A, Bruner A, Cooper P, Costanza R, Farber S, Green RE, Jenkins M, Jefferiss P, Jessamy V, Madden J, Munro K (2002) Economic reasons for conserving wild nature. Science 297:950-953. doi:10.1126/science.1073947

Bohlin T, Hamrin S, Heggberget T, Rasmussen G, Saltveit S (1989) Electrofishing - theory and practice with special emphasis on salmonids. Hydrobiologia 173:9-43. doi:10.1007/bf00008596

Boulinier T, Nichols JD, Sauer JR, Hines JE, Pollock KH (1998) Estimating species richness: the importance of heterogeneity in species detectability. Ecology 79:1018-1028. doi:10.1890 /0012-9658(1998)079[1018:esrtio]2.0.co;2

Buckland ST, Studeny AC, Magurran AE, Newson SE (2011) Biodiversity monitoring: the relevance of detectability. In: Magurran AE, McGill BJ (eds) Biological diversity: Frontiers in measurement and assessment. Oxford University Press, Oxford, pp 25-36

Colwell RK (2013) EstimateS: statistical estimation of species richness and shared species from samples. Version 9 and earlier. User's Guide and application Published at: http:// purloclcorg/estimates

Colwell RK, Coddington JA (1995) Estimating terrestrial biodiversity. In: Hawksworth DL (ed) Biodiversity: measurement and estimation. The Royal Society/ Chapman \& Hall, London

Colwell RK, Chao A, Gotelli NJ, Lin S-Y, Mao CX, Chazdon RL, Longino JT (2012) Models and estimators linking individualbased and sample-based rarefaction, extrapolation and comparison of assemblages. J Plant Ecol 5:3-21

Cote IM, Perrow MR (2006) Fish. In: Sutherland WJ (ed) Ecological census techniques: a handbook. Second Edition edn. Cambridge University Press, Cambridge

Dauble DD, Gray RH (1980) Comparison of a small seine and a backpack electroshocker to evaluate nearshore fish populations in rivers. Progress Fish-Cultur 42:93-95

Deacon AE, Shimadzu H, Dornelas M, Ramnarine IW, Magurran AE (2015) From species to communities: the signature of recreational use on a tropical river ecosystem. Ecol Evol 5: 5561-5572. doi:10.1002/ece3.1800

Dolan CR, Miranda LE (2003) Immobilization thresholds of electrofishing relative to fish size transactions of the. Am Fisheries Soc 132:969-976. doi:10.1577/t02-055

Dudgeon D, Arthington AH, Gessner MO, Kawabata Z-I, Knowler DJ, Lévêque C, Naiman RJ (2006) Freshwater biodiversity: importance, threats, status and conservation challenges. Biol Rev 81:163-182. doi:10.1017 /s1464793105006950

Dytham C (2011) Choosing and using statistics: A biologist's guide. Chichester, West Sussex, UK: Wiley-Blackwell

Ebner BC, Morgan D (2013) Using remote underwater video to estimate freshwater fish species richness. J Fish Biol 82: $1592-1612$

Ebner BC, Fulton CJ, Cousins S, Donaldson JA, Kennard MJ, Meynecke J-O, Schaffer J (2014) Filming and snorkelling as visual techniques to survey fauna in difficult to access tropical rainforest streams. Mar Freshwater Res 66:120-126

Fago D (1998) Comparison of littoral fish assemblages sampled with a mini-fyke net or with a combination of electrofishing and small-mesh seine in Wisconsin lakes. N Am J Fish Manag 18:731-738

Fièvet É, Bonnet-Arnaud P, Mallet JP (1999) Efficiency and sampling bias of electrofishing for freshwater shrimp and fish in two Caribbean streams, Guadeloupe Island. Fish Res 44:149-166. doi:10.1016/S0165-7836(99 )00058-2

Galili T (2015) Dendextend: an R package for visualizing, adjusting, and comparing trees of hierarchical clustering. Bioinformatics doi:10.1093/bioinformatics/btv428

Gerstner CL, Ortega H, Sanchez H, Graham DL (2006) Effects of the freshwater aquarium trade on wild fish populations in differentially-fished areas of the Peruvian Amazon. J Fish Biol 68:862-875. doi:10.1111/j.00221112.2006.00978.x

Głowacki Ł, Penczak T (2005) Species richness estimators applied to fish in a small tropical river sampled by conventional methods and rotenone. Aquat Living Resour 18:159-168

Gotelli NJ, Colwell RK (2001) Quantifying biodiversity: procedures and pitfalls in the measurement and comparison of species richness. Ecol Lett 4:379-391

Gotelli NJ, Colwell RK (2011) Estimating species richness. In: Magurran AE, McGill BJ (eds) Biological diversity: frontiers in measurement and assessment. Oxford University Press, Oxford, pp 39-54

Hendricks ML, Hocutt CH, Stauffer JR (1980) Monitoring of fish in lotic habitats. In: Hocutt $\mathrm{CH}$ and Stauffer JR (eds) Biological monitoring of fish. DC Heath, Lexington, MA pp 205-232

Lapointe NWR, Corkum LD, Mandrak NE (2006) A comparison of methods for sampling fish diversity in shallow offshore waters of large rivers. N Am J Fish Manag 26:503-513. doi:10.1577/m05-091.1

Lowe-McConnell RH (1975) Fish communities in tropical freshwaters: their distribution, ecology, and evolution. Longman, London

Maciolek JA, Timbol AS (1980) Electroshocking in tropical insular streams. Progress Fish-Cultur 42:57-58. doi:10.1577 /1548-8659(1980)42[57:eitis]2.0.co;2

Magurran AE (2004) Measuring biological diversity. Blackwell Publishing, Oxford

Magurran AE (2005) Evolutionary ecology: the Trinidadian guppy. Oxford series in ecology and evolution. Oxford University Press, Oxford

Mazzoni R, Fenerich-Verani N, Caramaschi EP (2000) Electrofishing as a sampling technique for coastal stream fish populations and communities in the southeast of Brazil. Rev Bras Biol 60. doi:10.1590/s003471082000000200003

Mercado-Silva N, Escandón-Sandoval DS (2008) A comparison of seining and electrofishing for fish community bioassessment in a Mexican Atlantic slope montane river. N Am J Fish Manag 28:1725-1732

Oksanen J, Kindt R, Legendre P, O'Hara B, Simpson GL, Solymos P, Stevens MHH, Wagner H (2008) vegan: Community Ecology Package. R package version 1.15-1, URL http://CRAN.R-project.org/package=vegan 
Onorato DP, Angus RA, Marion KR (1998) Comparison of a small-mesh seine and a backpack electroshocker for evaluating fish populations in a north-central Alabama stream. $\mathrm{N}$ Am J Fish Manag 18:361-373

Phillip DA, Taphorn DC, Holm E, Gilliam JF, Lamphere BA, López-Fernandez H (2013) Annotated list and key to the stream fishes of Trinidad \& Tobago. Zootaxa 3711:1-64

Pusey BJ, Kennard MJ, Arthur JM, Arthington AH (1998) Quantitative sampling of stream fish assemblages: singlevs multiple-pass electrofishing. Aust J Ecol 23:365-374. doi:10.1111/j.1442-9993.1998.tb00741.x

RCoreTeam (2016) R: A language and environment for statistical computing. http://www.R-project.org. R Foundation for Statistical Computing, Vienna

Snyder DE (2003) Invited overview: conclusions from a review of electrofishing and its harmful effects on fish. Rev Fish Biol Fish 13:445-453
Weyl O, Ellender B, Woodford D, Jordaan M (2013) Fish distributions in the Rondegat River, cape floristic region, South Africa, and the immediate impact of rotenone treatment in an invaded reach. Afr J Aquat Sci 38:201-209

Wiley ML, Tsai C-F (1983) The relative efficiencies of electrofishing vs. seines in piedmont streams of Maryland. N Am J Fish Manag 3:243-253

Willis SC, Winemiller KO, Lopez-Fernandez H (2005) Habitat structural complexity and morphological diversity of fish assemblages in a Neotropical floodplain river. Oecologia 142:284-295. doi:10.1007/s00442-004-1723-Z

WWF (2014) Living planet report 2014: species and spaces, people and places. Gland, Switzerland

Yoccoz NG, Nichols JD, Boulinier T (2001) Monitoring of biological diversity in space and time. Trends Ecol Evol 16:446453

Zalewski M (1983) The influence of fish community structure on the efficiency of electrofishing. Aquac Res 14:177-186 